\title{
Effects of Touch on Students' Stress, Happiness, and Well-Being During Animal-Assisted Activities
}

\author{
Laura Sokal $^{1}$, Brianne Bartel ${ }^{1} \&$ Taylor Martin ${ }^{1}$ \\ ${ }^{1}$ Faculty of Education, University of Winnipeg, Canada \\ Correspondence: Laura Sokal, Faculty of Education, University of Winnipeg, Canada.
}

Received: March 9, 2021

Accepted: April 7, 2021

Online Published: April 12, 2021

doi:10.20849/jed.v5i1.887

URL: https://doi.org/10.20849/jed.v5i1.887

\begin{abstract}
Post-secondary institutions across North America have adopted animal-assisted activities as a way to promote better mental health in their students. The current research study of 242 Canadian college and university students sought to contribute to our collective understanding of the aspects of the programs and characteristics of students that are related to promotion of better mental health in post-secondary students including decreased stress, and increased happiness and well-being. Results of a repeated measures design showed that students demonstrated greater positive effects on stress, happiness, and well-being when they touched dogs as compared to when they observed them. Furthermore, positive mental health outcomes were correlated with greater durations of contact as well as with higher levels of animal affiliation in students. Implications for post-secondary institutions are discussed.
\end{abstract}

Keywords: post-secondary students, mental health, animals, touch, duration, affiliation

\section{Introduction}

\subsection{Costs of Mental Disabilities}

Twenty years ago, in 2001, the World Health Organization (WHO) reported that one in four people globally experienced mental disabilities, and a broad collection of research since that time has supported an escalation in concerns about mental health. More recently, the WHO (2019) showed that the annual, global costs of anxiety and depression alone were over a trillion US dollars.

The financial costs of mental disabilities are not restricted to the health care system, as mental health issues affect other settings in which those affected take part—workplaces, schools, and communities. Of particular concern in the current study are mental health issues in young adults, including post-secondary students. Cribb, Ovid, \& Bigham (2017) surveyed post-secondary institutions and found that the vast majority had increased their budgets to student services departments by a third over the past five years for the specific purposes of meeting increasing demands related to mental health in the student population, including both counselling for all students, as well as accessibility support for students with mental disabilities. A 2019 survey about the health of Canadian post-secondary students (ACHA-NCHA, 2019) showed that over half of the current students had been treated for a disability within the past year, with $24.2 \%$ having experienced depression and $34.6 \%$ having experienced anxiety - the same mental disabilities cited in the 2019 WHO report as contributing substantially to health care costs. Although these two diagnoses represent only a portion of the range of possible diagnoses, they are the most common disabilities affecting Canadian university students and draw significantly from university budgets (ACHA-NCHA, 2019). Given that students in the ACHA-NCHA (2019) survey reported experiencing both conditions at severe enough levels to affect academic performance, the cited healthcare costs are further compounded by the loss in the economic contributions of students who fail to complete their studies due to their mental disabilities.

It is important to note that although there is documented high prevalence of mental disabilities in post-secondary institutions, they are no more common in this setting than in other settings where young people are the majority (Wiens et al., 2020). However, the transition to university or college coincides with other new experiences for many students, such as moving away from the family home, making new friends, living in new settings with limited financial means, and taking on responsibilities such as maintaining a home (Henderson et al., 2018; Nunes et al., 2014), which may add additional pressure for these young people (Brougham et al., 2009). Indeed, 
stress has been acknowledged as the main barrier to academic success in university students (ACHA-NCHA, 2019). Although not recognized as a disability, stress can contribute to the development of disabilities such as anxiety disorders and therefore serves as a threat to students' success and well-being at school.

\subsection{Mental Health During the COVID-19 Pandemic}

While concerns about student mental health have garnered increasing attention over the past 20 years, it is clear that these concerns have escalated at unprecedented rates more recently as a result of COVID-19. A survey conducted by the Canadian Association for Mental Health (2020) showed that in June 2020 during the first wave of COVID-19, 27.2\% of Canadians aged 18-39 reported experiencing moderate to severe anxiety-a proportion higher than any other reported age range in that study. Of those experiencing moderate to severe anxiety, $46.1 \%$ were very worried about finances, $37.3 \%$ were very worried about themselves or someone close to them contracting COVID-19, and $27.7 \%$ had lost their job or were no longer working as a result of the pandemic. Clearly, the pandemic has added to the stressors typically experienced by many post-secondary students, and may result in severe and lasting impacts on their post-secondary success.

Given that addressing mental health needs is more important than ever during a pandemic, it is ironic that the social distancing required to address COVID -19 is antithetical to the accepted practices that foster mental health Common practices for promoting happiness and decreasing loneliness are activities that involve social connectedness (Satici et al., 2016), and these practices are curtailed for the purposes of social distancing required to prevent disease transmission. Therefore, it is important that post-secondary institutions look for safe, socially-distanced ways to address student mental health, both for students with mental disabilities and for those without.

\subsection{Theoretical Underpinnings and Applications in Post-Secondary Settings}

An important distinction is that between mental disabilities and mental health. While once conceptualized as opposite poles on the same continuum, more recent theorizing recognizes more dynamic relationships between these constructs. A model proposed by Keyes (2002) captures these relationships. Keyes proposed that mental disabilities and mental wellness are best understood as two intersecting continua. People with diagnosed mental disabilities can be represented as 'flourishing' when their disabilities are managed or as 'languishing' when they are not. Likewise, those without diagnoses of mental disabilities can be represented as flourishing or languishing. As a current case in point, many individuals who typically experienced good mental health before the pandemic have found that the significant and lasting changes necessitated by COVID-19 have elevated their loneliness and worry. The Keyes model captures these situations, in that a lack of a diagnosis is not an indication of good mental health per se, just as a diagnosis of a mental disability — such as anxiety or depression - is not viewed as synonymous with poor mental health. Whether a person has a diagnosed mental disability or not, mental health is recognized by the WHO as "a state of well-being in which an individual realizes his or her own abilities, can cope with normal stresses of life, can work productively and fruitfully, and is able to make a contribution to his or her community" (2004, p. 12). In effect, mental health is a state where a person has adapted to the demands of their own life and can function effectively in that context. Importantly, mental health-like physical health -is the result of the routines and practices that support it, and in accordance with this understanding, the WHO (2001) has encouraged individuals to address their mental health needs in affordable and existing ways.

While universities in the past have framed their approaches to student mental health within a medical model of reactive accommodation - and in many ways still do (Sokal et al., in press; Dolmage, 2017), more recent concepts of mental health and wellness based in the Keyes model have made their way into post-secondary institutions. By supporting all students in their efforts to 'flourish' rather than 'languish', universities not only complement expensive, restrictive, and reactive accommodations, they also support students in remaining resilient during the common challenges of the transition from adolescence to adulthood. One approach to supporting these efforts is offering students opportunities to spend time with animals.

\subsection{Animal-Assisted Activities}

Based on the persuasive evidence that pet ownership is associated with better physical and mental health (Allen et al., 2002; Friedmann \& Thomas, 1995; Freidmann \& Tsai, 2006), as well as the broad appeal and low cost of such programs, many North American universities and colleges have begun to offer dog visitation programs to their students (Binfet et al., 2018; Crossman et al., 2015). These programs can be categorized as animal-assisted activities (AAAs), as AAAs are typically informal interactions that focus on relationships and do not require therapeutic goals or the presence of a therapist (Walsh, 2009). Research on these informal activities in university and college students has shown that they result in decreased student loneliness (Stewart et al., 2014), decreased sadness and anxiety (Emily, 2019), and decreased stress-as measured both through self-report and 
physiological measures (Muckel \& Lasikiewicz, 2017). In this way, they fit nicely with Keyes' (2002) model of mental health, in that they are intended to promote mental health in both students with and without mental disabilities.

\subsection{Design Concerns in AAAs}

Despite these overall positive effects, reservations remain based on three reviews of the literature (Crossman, 2017; Nimer \& Lundahl, 2007; Stern \& Chur-Hansen, 2013) related to AAAs. Of particular interest in the current study are three of these concerns. First, Crossman's 2017 review of AAAs pointed out the lack of control groups in many commonly cited studies of the effects of AAAs, therefore calling into question the confidence in these findings. Second, Stern \& Chur-Hansen (2013) cautioned that many AAA studies have failed to measure participants' prior affiliation with animals, raising concerns about the generalizability of the findings and questioning whether they are an artifact of sampling bias. Third, Crossman (2017) criticized the lack of description of the actual processes that took place during AAAs in many studies and encouraged isolation of the variables that foster the reported positive outcomes. In particular, Ward-Griffin et al. (2017) encouraged researchers to investigate the importance of touch in terms of its influence on the positive outcomes reported in AAA research. Our previous research (Sokal \& Kahl, 2019) on AAAs with refugee children, as well as research by others (Hart \& Yamamoto, 2015) has suggested that touching animals may be especially salient in AAAs. Likewise, Handlin et al. (2012) provided biological evidence that touching animals resulted in decreased cortisol levels as well as increased oxytocin. However, other research has suggested that spending time with fish, which are rarely touched, can lead to feelings of calmness in children (Sokal, 2020). Considered together, these design limitations as well as the conflicting results provoke less certainty about previous findings related to human-animal interaction studies.

\subsection{Exemplar and Recent AAA Study Designs}

Several recent, high quality studies have addressed some of these design concerns and have suggested directions for further research. For example, Binfet and Passmore (2016), Crossman et al., (2015), and Ward-Griffin et al. (2017) all conducted studies with random assignment and included control groups. However, even these very strong studies had research limitations. For example, the first study was limited to first-year students who met eight times, so the findings of this study specific to decreasing loneliness do not easily generalize to other students who take part in the one-time, short AAAs more typically offered in post-secondary institutions. Likewise, Crossman et al. (2015) studied medical students, again challenging generalizability of the benefits of AAAs to the moods and levels of anxiety of students in other university programs. Finally, while Ward-Griffin et al. (2017) met many of the criteria of excellence in design, they did not measure the duration of the visits nor isolate the specific aspects of the AAA visits that led to the positive outcomes in students' happiness and stress-limitations they suggested that future research should address.

Recent studies of AAAs continue to range in quality and design. For example, Thelwell (2019) recently published a small $(N=82)$ controlled study of students' anxiety and mood when touching real animals for a ten-minute period and when watching videos of animals. This study considered prior animal affiliation as well as effects of interacting with animals as opposed to watching them, one of the first studies to do so. However, the durations of the visits were pre-set at ten minutes, which is not the typical set up of university-based AAAs where students choose the duration of their visits, and the sample size was small. Likewise, Spruin and her colleagues (2020) published a small study $(N=94)$ that compared the effects of AAAs, mindfulness, and control activities on students' mood and anxiety. They found that mindfulness and AAAs were equally effective in fostering positive effects as compared with the control group. However, again, the duration of contact was controlled, and this design feature therefore limited generalizability to non-experimental AAA settings.

\subsection{The Current Study}

In seeking to contribute to the literature, we designed a study to address three of the main concerns (control group, prior affiliation, effects of touch) expressed in reviews of AAA studies (Crossman, 2017; Nimer \& Lundahl, 2007; Stern \& Chur-Hansen, 2013). Moreover, the current study sought to build upon the high-quality studies of AAAs conducted by Binfet and Passmore (2016), Crossman et al. (2015), and Ward-Griffin et al. (2017) by creating a controlled, authentic, within-subject design that isolates the effects of touch and the duration of the treatment, while investigating students' prior attitudes toward animals.

In keeping with the findings that depression and anxiety are the most prevalent mental disabilities presented at Canadian university student services offices (ACHA-NCHA 2019), and with acknowledgement that well-being is a proxy for 'flourishing' as represented in the Keyes (2002) model, we endeavored to measure student state happiness, stress, and well-being prior to AAAs, after a time-limited observational stage of AAAs, and again 
after a student-selected duration of touching dogs during a subsequent stage of the AAA study. Given that previous research has expressed concerns over conflation of happiness and wellbeing as constructs (Linton et al., 2016), we were cognizant to measure each separately. Moreover, we recognized that students both with and without depression can sometimes feel unhappy and that students both with and without anxiety can sometimes feel stress. In keeping with the Keyes model that recognizes the intersection of mental health and mental disability as well as their varied representations in university students, we sought to measure the effects of a universal, opt-in program to enhance the overall mental health of all students, with specific attention to their state happiness, stress, and well-being.

\subsection{Hypotheses}

Given past research showing the effects of AAAs on student well-being as well as the directions for further investigations outlined in previous research involving AAAs at post-secondary schools, the primary hypotheses were:

H1: Students will make significantly greater increases in happiness and well-being, and decreases in stress when touching the animals than when observing them;

H2: Longer durations of touching the animals will be significantly and positively correlated with greater perceived happiness and well-being and lower stress than shorter durations of touching the animals;

H3: Greater affiliation for dogs at study onset will be significantly and positively correlated with greater changes in perceived happiness and well-being and lower stress.

\section{Method}

\subsection{Participants}

The participants included 242 students, including 76 college students and 166 university students who attended one of five school-based AAA events. For more detailed descriptions of these students, please see Table 1.

Table 1. Demographic information about participants

\begin{tabular}{|c|c|c|c|}
\hline Gender & Number & Years of Schooling & Number \\
\hline Male & 91 & 1 or less & 116 \\
\hline Female & 136 & 2 & 38 \\
\hline Other & 7 & 3 & 28 \\
\hline Prefer not to say & 1 & 4 & 17 \\
\hline Missing & 7 & 5 & 9 \\
\hline Age & & 6 & 8 \\
\hline $17-18$ & 54 & 7 & 2 \\
\hline $19-20$ & 73 & Missing & 24 \\
\hline $21-22$ & 37 & Setting & \\
\hline $23-24$ & 39 & College Visit 1 & 76 \\
\hline $25-26$ & 14 & University Visit 1 & 57 \\
\hline $27-33$ & 14 & University Visit 2 & 53 \\
\hline Missing & 11 & University Visit 3 & 30 \\
\hline Student Origin & & University Visit 4 & 23 \\
\hline City & 154 & Have a Pet & \\
\hline Rural, within province & 42 & Yes & 164 \\
\hline Other province & 5 & No & 74 \\
\hline International & 31 & Missing & 5 \\
\hline \multirow[t]{4}{*}{ Missing } & 10 & Live with a Pet & \\
\hline & & Yes & 126 \\
\hline & & No & 92 \\
\hline & & Missing & 24 \\
\hline
\end{tabular}




\subsection{Instruments}

We have used some of the same instruments in our previous studies of the effects of AAAs with other populations and have provided detailed descriptions in those reports (Sokal, 2020; Sokal \& Kahl, 2019, Sokal \& Martin, 2021), and we summarize the descriptions of the measures here. In the current study, we were interested in measuring post-secondary students' stress, happiness, and well-being.

To measure well-being, we chose the World Health Organization's WHO5, given that independent researchers (Topp et al., 2015) have verified that it is a reliable and valid measure of well-being in a wide variety of settings, and it can measure change that results from short-term treatments like AAA visits. As expressed in our previous work, this measure is a good fit for this research program, as it aligns with the Keyes (2002) model of well-being, as well as the WHO definition of mental health used to underpin our investigations. Moreover, it is quick to administer, so recruitment of participants is facilitated. We altered the WHO5 by changing the wording to reflect students' current states versus retrospective stages. For each question, rather than asking how often students felt a specific way "over the past two weeks," we asked them how they were feeling "right now." A six-point Likert scale ranging from 1 (strongly disagree) to 6 (strongly agree) was used in each case. We omitted one of the five statements because its temporal referent was too long for the current intents and purposes: "My daily life has been filled with things that interest me." We calculated Cronbach alpha values for the altered scale and found the revised scale had good reliability (alpha $=.76$ ).

We added two statements to measure the global constructs of stress and state happiness. We chose to measure stress, as research has shown it is the most commonly reported challenge to students' academic achievement (ACHA-NCHA, 2019). We chose to measure state happiness, as other studies tend to measure effects on negative variables such as anxiety or general categories such as 'positive moods.' An exception is Thelwell (2019) who conducted an AAA study in the UK. She found that the students who interacted with real dogs demonstrated higher gains in 'joviality' than did students who watched videos about dogs. Given that our study has a similar comparison, but uses observations of real dogs rather than videos of dogs, examination of happiness (synonymous with the British 'joviality') was investigated.

Single-item measures of latent variables have been used successfully in recent AAA studies (Barker et al., 2016; Binfet et al., 2018). Furthermore, recent research has validated their use of the specific constructs of stress and coping (Eddy et al., 2019; Zimmerman et al., 2006). A final question was added as quality control at the end of each inventory to ensure that the participants had not petted or touched animals before joining the study (pre-visit inventory); and had not petted or touched animals during the no petting/observation treatment (mid-visit inventory); and to describe the types of animals and interactions during the AAA session (post-visit inventory).

\subsection{Design}

The current study was approved in a two-level process (departmental and Senate committees) by the primary investigator's institution as meeting all ethical criteria expected in university-based research in Canada (Human Ethics certificate \#13453) and funded by a Social Sciences and Humanities Research Council of Canada Explore grant. The study took place at post-secondary institutions in a mid-sized Canadian city. These institutions - one university and one college-_offered drop-in AAA sessions several times each year and utilized the same canine-handler pairs from St. Johns Ambulance. The sessions took place for 1.5 hours over the lunch hour in a student common room. Each visit included five canine-handler pairs whose dogs had been vetted for behaviour through rigorous testing by St. Johns Ambulance. All dogs lived with their handlers when not volunteering at community events.

Student research assistants (RAs), who were previously trained and certified in the CORE tutorial for the ethical treatment of human research participants based on the Tri-Council Policy Statement 2, set up a table outside the AAA room during one visit at the college and four visits at the university during the 2019-2020 school year. One student RA remained at the table and one student RA approached potential participants as they approached the door to the AAA room. Participants were invited to participate in a study about the effects of animal visits on students' well-being, told it would add 20 minutes to their visit that day, and offered five dollars cash as an honorarium.

Once students accepted the invitation, they were directed to the second student RA at the research table. Please see Figure 1. There they were given the consent form, it was explained, and their questions were answered. They then initialed the consent form and filled out the pre-visit inventory, including eight demographic questions and seven questions measuring happiness, stress, and well-being. They were then given a participant number, asked to enter the AAA room for a period of ten minutes, but instructed to refrain from touching the animals. 


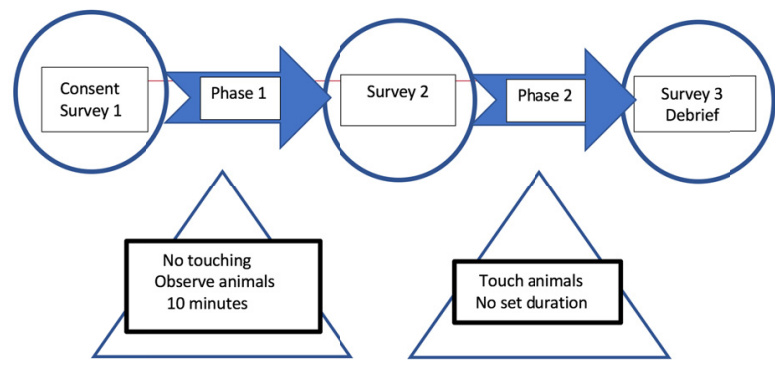

Figure 1. Study design

After ten minutes, they returned to the RA table, submitted their participant number, they again filled out the last seven questions of the inventory, and the time was recorded. The participants were then instructed to re-enter the AAA room and interact with the animals as they wished, including touching and petting them. This visit could last as long as desired by the participants, up until the AAA room closed. Once they were finished, they returned to the RA table, provided their participant number, the time was recorded, they again filled out the last seven questions of the inventory. They were given $\$ 5$ and were invited to take printed information about student services offered at their institution from the display on the RA tables. There were no unexpected incidents involving students becoming upset or raising any ethical concerns at any of the AAA visits.

\section{Results}

The data sets were organized and entered into an Excel spreadsheet by the same student RAs who collected the data. These data were cleaned, and any unclear questionnaire responses were examined and discussed between the primary investigator and RAs. The data were imported into SPSS, and it was used to conduct a series of analyses to address the three hypotheses.

In order to test the first hypothesis, we ran a series of paired $t$-tests, comparing the magnitude of change in the observation phase (phase 1 in Figure 1) with the magnitude of change in the touching phase (phase 2 in Figure 1). Table 2 provides the mean starting values and means ending values for both phase 1 and 2 , as well as the mean magnitude of change in each phase. The $t$-tests indicated that there were statistically significant differences in the magnitude of change in happiness, stress, and well-being between the phase 1 and phase 2 values. Examination of the means revealed that in all three cases, the magnitude of change was greater in the touching phase than in the observational phase - specifically, increased happiness, decreased stress, and increased well-being. See Table 2 .

Table 2. T-test comparing magnitude of change in the observational phase and the touching phase

\begin{tabular}{llllll}
\hline Happiness & Mean & SD & $\boldsymbol{t}$ & $\boldsymbol{d} \boldsymbol{f}$ & sig. \\
\hline At Onset of Observation & & & & \\
\hline At Completion of Observation & 4.46 & 0.981 & & \\
\hline Mean Change during Observation & 4.52 & 1.079 & & & \\
\hline At Completion of Touching & 0.0513 & 1.07125 & & \\
\hline Mean Change during Touching & 5.27 & 0.892 & & \\
\hline -test Observation change/Touching Change & & & & & \\
\hline Stress & & & & & \\
\hline At Onset of Observation & 3.98 & 1.000 & & \\
\hline At Completion of Observation & 3.43 & 1.2987 & & & \\
\hline Mean Change during Observation & -0.5447 & 1.11762 & & & \\
\hline At Completion of Touching & 2.54 & 1.172 & & & \\
\hline
\end{tabular}




\begin{tabular}{|c|c|c|c|c|c|}
\hline Mean Change during Touching & -1.4426 & 1.20181 & & & \\
\hline$T$-test Observation change/Touching Change & & & 11.012 & 234 & 0.000 \\
\hline \multicolumn{6}{|l|}{ Well-being } \\
\hline At Onset of Observation & 3.7876 & 0.91491 & & & \\
\hline At Completion of Observation & 3.9713 & 0.986 & & & \\
\hline Mean Change during Observation & 0.1934 & 0.72859 & & & \\
\hline At Completion of Touching & 4.6472 & 0.8074 & & & \\
\hline Mean Change during Touching & 0.8771 & & & & \\
\hline$T$-test Observation change/Touching Change & & & -14.325 & 233 & 0.000 \\
\hline
\end{tabular}

In order to address the second and third hypotheses, a correlation table was calculated to determine the relationship between prior affiliation with dogs, duration of the touching phase, and the magnitude of change during the touching phase of the three dependent variables (please see Table 3).

Table 3. Correlations between touch, duration, and changes to happiness, stress and well-being

\begin{tabular}{|c|c|c|c|c|c|}
\hline & & 1 & 2 & 3 & 4 \\
\hline \multirow[t]{3}{*}{ 1. Duration of touching phase } & Pearson Correlation & & & & \\
\hline & Sig. (2-tailed) & & & & \\
\hline & $N$ & & & & \\
\hline \multirow[t]{3}{*}{ 2. Dog Affiliation Score } & Pearson Correlation & $.194 * *$ & & & \\
\hline & Sig. (2-tailed) & 0.003 & & & \\
\hline & $N$ & 235 & 237 & & \\
\hline \multirow[t]{3}{*}{ 3. Change in Happiness } & Pearson Correlation & $.214^{* *}$ & $.171^{* *}$ & & \\
\hline & Sig. (2-tailed) & 0.001 & 0.009 & & \\
\hline & $N$ & 234 & 235 & & \\
\hline \multirow[t]{3}{*}{ 4. Change in Stress } & Pearson Correlation & $-.135 *$ & -0.093 & $-.336 * *$ & \\
\hline & Sig. (2-tailed) & 0.038 & 0.154 & 0 & \\
\hline & $N$ & 235 & 236 & 235 & \\
\hline \multirow[t]{3}{*}{ 5. Change in Well-being } & Pearson Correlation & $.198 * *$ & $.159 *$ & $.407 * *$ & $-.301 * *$ \\
\hline & Sig. (2-tailed) & 0.002 & 0.015 & 0 & 0 \\
\hline & $N$ & 234 & 235 & 234 & 235 \\
\hline
\end{tabular}

* Correlation is significant at the 0.05 level (2-tailed).

** Correlation is significant at the 0.01 level (2-tailed).

\section{Discussion}

\subsection{Design Benefits}

One of the goals of the current study was to address some of the design limitations of previous AAA studies, so we will begin with a discussion of the benefits of using the current design. The repeated measures experimental design used in the current study was carefully constructed to build on high-quality prior studies while addressing the criticism expressed in several reviews of AAA study designs (Crossman, 2017; Nimer \& Lundahl, 2007; Stern \& Chur-Hansen, 2013). The selected design provided a control group while at the same time ensuring sufficient power for statistical analysis. By incorporating an observation stage before the interaction stage during which the students could touch the animals, we gained several benefits. 
First, we did not divide the interested students into separate control and treatment groups, which would have decreased the size of each group (Charness et al., 2012). Instead, the students served as their own controls, and the within-subject design we used ensured that the treatment and control groups were therefore perfectly matched in terms of other variables such as gender and prior affiliation for animals. While the advantage of this design is that it reduces the error of individual differences found in between-subject random assignment designs, we accepted the risk that participants could become fatigued or have carry-over effects from the observation phase to the interaction phase of the study (Charness et al., 2012).

Second, an important advantage of this design is that it allowed us to isolate the effects of touching the animals from the effects of being in their presence, within each individual, therefore addressing the concern of Crossman (2017) and Ward-Griffen et al. (2018) that research studies should isolate the aspects of AAA that are associated with the positive outcomes found in the literature.

Third, we avoided the ethical concern of denying access to the animals to the students in the control group, which has been associated in prior studies with increased student stress (Binfet, 2017). This was a concern expressed by the research team, as distressed students in our study may have become more distressed if a longer waiting time was used. Ward-Griffin et al. (2018) used a three-week delayed treatment control group in their study and found that the control group students had a less positive response to AAAs, an ethical challenge we wished to avoid.

Fourth, by measuring the time when each survey was administered, we were able to control the duration of time participants spent watching the animals, and measure the duration of time that participants spent interacting with the animals, therefore addressing the design criticism of Nimer \& Lundahl (2007) and Ward-Griffen et al. (2018). Furthermore, by not limiting the latter, we were able to link any potential findings to the durations chosen by the students, therefore providing opportunities for generalization to authentic, post-secondary-based AAAs, which are often of duration of the students' choosing.

Fifth and finally, by ensuring we controlled for differences in canine affiliation of students at onset, we addressed potential confounding variables left unaddressed in some previous studies (Stern \& Chur-Hansen, 2013).

\subsection{Effects of Touch}

Our study resulted in several significant findings that contribute to our understanding of the effects of animal interactions on post-secondary students. Our findings build on the high-quality work of Ward-Griffin et al. (2018), in that they offer greater understanding of the specific factors implicit in AAAs that contribute to the outcomes as well as offering new information about the effects of duration of contact. First, our findings suggest that touch is a significant factor in students garnering positive effects from animal-human interactions. While observing animals did result in higher self-perceived happiness and well-being and lower self-perceived stress in students, these effects were magnified when the students touched the animals. This finding is similar to that of Thelwell (2019) who also found more positive effects resulted from touching real animals than from watching videos of them. These findings support our past work with refugee children (Sokal \& Kahl, 2019), as well as work by others who examined the effects of touching animals on human physiological responses such as decreased cortisol and increased oxytocin levels (Handlin et al., 2012) —chemicals associated with positive feelings. These findings have important practical implications, in terms of AAAs in post-secondary settings. Specifically, being as contact is important, organizers of these events should ensure that there are sufficient numbers of dog/handler teams to allow students free access to petting opportunities. Given that the benefits of touching the animals significantly outweigh the benefits of observing others with the animals - both real animals and videos of animals - AAA events should plan to maximize opportunities for students to touch the animals.

\subsection{Effects of Duration}

Second, the magnitudes of changes in the dependent variables of stress, happiness, and well-being were significantly and positively correlated with the durations of contact. This is an important finding, given issues around duration in previous studies (Binfet \& Passmore, 2016; Ward-Griffin et al., 2017). Given that the average duration that students chose to spend with the animals was only about 11 minutes, and some students chose to spend fewer than five minutes with them, this finding has implications in other AAA settings such as schools, childcare centres, and hospitals, where durations of visits are sometimes limited. Likewise, in a classroom setting where large groups of children are trying to pet one dog, the opportunities for human-animal physical contact are somewhat limited. Given the importance of touch demonstrated here and in other studies as well as our findings related to duration, it is important that the conditions of AAAs support both adequate time and adequate opportunities for contact in order for the full benefits to be garnered. Future research should examine duration of touch to determine the "sweet spot" where positive outcomes are maximized within the greatest efficiencies 
regarding duration.

\subsection{Effects of Animal Affiliation}

Finally, it is noteworthy that we found greater benefits in changes to happiness and well-being in students who began the study with greater affiliations for dogs (Thelwell, 2019). This is an important consideration (Stern \& Chur-Hansen, 2013), as we cannot assume that touching animals in general or dogs in particular would yield the same outcomes for students who are uncomfortable around animals or specifically around dogs. Moreover, there was no significant correlation between changes in stress during the touching phase and animal affiliation. That is, students' decreases in stress were not correlated with their level of preference for dogs before the study. This finding was unexpected, however an examination of the means and range of affiliation levels in the students who participated may shed some light on this finding. The mean animal affiliation of students who attended the AAA events was $9.19(S D=1.18)$ from a possible high of 10 , indicating that overall, the students who attended these events had a strong liking for dogs. Of the 237 students who provided animal affiliation data prior to the event (range 4-10), only 7 students scored their affiliation lower than 7, and 176 students provided a value of $9(n=41)$ or $10(n=135)$. Clearly, the participants who chose to partake in the AAA events overwhelmingly indicated strong affiliation for dogs, and it would be tempting to attribute the lack of a significant correlation between affiliation and changes to stress levels to the small range of affiliation in the sample. However, this explanation is insufficient, as the same small range of affiliation values supported significant correlations with increased happiness and well-being. Significant correlations that were demonstrated between affiliation and happiness and well-being that did not manifest in similar a relationship with stress will require further investigation.

\section{Limitations}

All research studies have limitations, and ours is no exception. First, the findings are based on self-report. It is possible that students' perceptions of their own happiness, stress, and well-being would not match with more objective measures, although other AAA studies with both self-report and objective physiological testing of neuropeptides (Handlin et al., 2012) and blood pressure (McDonald et al., 2017) have shown a strong correlation between self-reported and physiological data. Second, the animals that the students petted were all dogs. It is possible that the findings would have been different if other animals had been included in the study. Third, it is possible that the stronger findings generated in the touching phase were a collective response to both phases together. Even though the data used for comparison isolated magnitude of change in each stage, it is possible that the observation stage primed the students toward greater results in the touching phase and that our design resulted in carry-over effects (Charness et al. 2012). Alternatively, it is also possible that the phase 2 results were suppressed by the effects of fatigue, although this seems unlikely given the positive and significant changes indicated by the data generated in phase 2. Fourth, some students are not comfortable with animals for medical, cultural, or religious reasons. It is unlikely that these students would choose to attend an AAA session, and it would be important to provide other types of activities that support mental health for these students. Finally - and importantly - the animals who served in the current study were family pets who had undertaken strict testing before being certified as therapy dogs. These dogs were limited in terms of their duration of service each month, and their handlers were cognizant of their animals' feelings of stress or fatigue, as indicated by handlers curtailing the participation of their animals when these limitations were exhibited. It is important to recognize the effects of such work on animals (Sokal, 2020, Sokal \& Martin, 2021), and to balance animal welfare alongside human welfare in AAA activities, as the effects on the animals serving as therapy dogs during AAAs are still unclear (Melco et al., 2020). Being as recent research has shown that animals' stress levels mirror those of their owners and has supported animals' sensitivity to humans' emotions (Sundman et al., 2019), subsequent studies that concurrently examine this variable would add significantly to our understanding of reciprocal effects of AAA. Furthermore, a video record of visits in future AAA studies would not only be useful in examining the signs of stress in the animals, but would also provide data about the possible confounding effects of the handlers when the students interact with the dogs.

\section{Future Directions and Conclusions}

The limitations of the current project provide suggestions for future research designs. First, we suggest that physiological data be gathered alongside self-report data to further validate the findings. Second, we suggest that future research incorporate other types of animals, both those with fur and those without fur. Research on other animals in school-based AAA programs would allow greater understanding of how the type of animal-and whether that animal has fur- might affect the outcomes. One participant in the current study commented, "Dogs are relaxing animals. However, when I pet cats I feel more relaxed and unstressed," suggesting that this is an interesting direction to pursue. Moreover, given that the most common pet allergy in Canadian children relates to 
allergies to the animals' fur (Sokal, 2020), it would be interesting to determine whether the effects of petting non-furry animals or robotic animals (Varley, 2019) would be similar to those outcomes with dogs, and if so, to offer these types of experiences to students with fur allergies. Third, future studies should incorporate a cross-over design to rule out carry-over effects. Finally, future studies should aim to investigate the notion of an optimal duration of contact in the context of efficiencies in maximizing positive human effects while minimizing any potential negative effects of AAAs on animals.

Notwithstanding these limitations, our findings support campus-based, canine-human AAAs as a universal, low-cost, opt-in means of increasing happiness and well-being while concurrently decreasing stress in post-secondary students. Given the pre-pandemic awareness of the urgency of addressing student mental health and well-being (ACHA-NCHA, 2019) as well as the escalating needs resulting from the pandemic (Canadian Association for Mental Health, 2020), AAAs can provide a viable complement to current programming intended to promote student mental health. Considered together, these findings support the use of AAAs for promoting mental health in post-secondary students in typical day-to-day schooling: they suggest that for students with high affiliation for animals, spending time touching animals can result in more positive mental health, even in the case of short interactions. Moreover, given that touch and proximity to other humans has been minimized due to the current COVID-19 pandemic, the opportunity to find comfort from spending time touching animals is especially important at this time of high stress and uncertainty. Our research shows that short encounters with unfamiliar animals can generate positive results on student mental health and well-being.

\section{References}

Allen, K. M., Blascovich, J., \& Mendes, W. B. (2002). Cardiovascular reactivity in the presence of pets, friends, and spouses: The truth about cats and dogs. Psychsomatic Medicine, 64(5), 727-739.

American College Health Association [ACHA-NCHA]. (2019). National college health assessment Canadian reference group. Retrieved from http://www.cacuss.ca/files/Research/NCHA-iiSpring

Barker, S., Barker, R. T., McCain, N. L., et al.. (2016). A randomized cross-over exploratory study of the effect of visiting therapy dogs on college student stress before final exams. Anthrozoos, 29, 35-46.

Binfet, J. T. (2017). The effects of group-administered canine therapy on university students' wellbeing: A randomized controlled trial. Anthrozoös, 30(3), 397-414.

Binfet, J. T., \& Passmore, H. A. (2016). Hounds and homesickness: The effects of an animal-assisted therapeutic intervention for first-year university students. Anthrozoös, 29(3), 441-454.

Binfet, J., Passmore, H., Cebry, A., Struik, K., \& McKay, C. (2018). Reducing university students' stress through a drop-in canine-therapy program. Journal of Mental Health 27(3), 197-204. https://doi.org/10.1080/09638237.2017.1417551

Brougham, R. R., Zail, C. M., Mendoza, C. M., \& Miller, J. R. (2009). Stress, sex differences, and coping strategies among college students. Current Psychology, 28, 85-97. https://doi.org/10.1007/s12144-009-9047-0

Canadian Association for Mental Health [CAMH]. (2020). COVID-19 national survey dashboard. Retrieved from https://www.camh.ca/en/health-info/mental-health-and-covid-19/covid-19-national-survey

Charness, G., Gneezy, U., \& Kuhn, M. (2012). Experimental methods: Between-subject and within-subject design. Journal of Economic Behavior and Organization, 81, 1-8.

Cribb, R., Ovid, N., Lao, D., \& Bigham, B. (2017, May). Demand for youth mental health services is exploding. How universities and business are scrambling to react. Toronto Star. Retrieved from https://www.thestar.com/news/canada/2017/05/29/youth-mental-health-demand-is-exploding-how-universiti es-and-business-are-scrambling-to-react.html

Crossman, M. K. (2017). Effects of interactions with animals on human psychological distress. Journal of Clinical Psychology, 73(7), 761-784.

Crossman, M., Kazdin, A., \& Knudson, K. A. (2015). Brief unstructured interaction with a dog reduces distress. Anthrozoös, 28(4), 649-659. https://doi.org/10.1080/08927936.2015.1070008

Dolmage, J. (2017). Academic ableism: Academics and higher education. Ann Arbor: University of Michigan Press. https://doi.org/10.3998.mpub/9708722

Eddy, C., Herman, K., \& Reinke, W. (2019). Single-item teacher stress and coping measures: Concurrent and predictive validity and sensitivity to change. Journal of School Psychology, 17-32. 
Emily, L. R. T. (2019). Paws for thought: a controlled study investigating the benefits of interacting with a house-trained $\operatorname{dog}$ on university students' $\operatorname{mood}$ and anxiety. Animals, $9(10)$. https://doi.org/10.3390/ani9100846

Friedmann, E., \& Thomas, S. (1995). Pet ownership, social support, and one-year survival acute myocardial infarction in the cardiac arrhythmia trial suppression trial. American Journal of Cardiology, 76, 1213-1217.

Friedmann, E., \& Tsai, C.-C. (2006). The animal-human bond: Health and wellness. In A. Fine (Ed.), Animal-assisted therapy: Theoretical foundations and practice guidelines (2nd ed., pp. 95-117). San Diego: Academic Press.

Handlin, L., Nilsson, A., Ejdeback, M., Hydbring-Sandberg, E., \& Uvnas-Moberg, K. (2012). Associations between the psychological characteristics of the human-dog relationship and oxytocin and cortisol levels. Anthrozoos, 25(2), 215-228. https://doi.org/10.2752/175303712x13316289505468

Hart, L., \& Yamamoto, M. (2015). Recruiting psychosocial health effects of animals for families and communities: Transitions to Practice. In A. H. Fine (Ed.), Handbook of animal-assisted therapies: Foundations and guidelines for animal-assisted interventions (4th ed., pp. 53-72). Waltham, MA: Elsevier.

Henderson, L., Thompson, K., Hudson, A., Dobson, K., Chen, S., \& Stewart, S. (2018). An analysis of campus culture, mental health, and drinking at three Canadian universities. Canadian Journal of Community Mental Health, 37(3). https://doi.org/10.7870/cjcmh-2018-013

Keyes, C. L. M. (2002). The mental health continuum: from languishing to flourishing in life. Journal of Health and Social Research, 43, 207-222.

Linton, M., Dieppe, P., \& Medina-Lara, A. (2016). Review of 99 self-report measures for assessing well-being in adults: exploring dimensions of well-being and developments over time. BMJ Open, 6. e010641. https://doi.org/10.1136/bmjopen-2015-010641

McConnell, A., Brown, C., Shoda, T., Stayton, L., \& Martin, C. (2011). Friends with benefits: On the positive consequences of pet ownership. Journal of Personality and Social Psychology, 101(6), 1239-1252. https://doi.org/10.1037/a0024506

McDonald, S., McDonald, E., \& Roberts, A. (2017). Effects of novel dog exposure on college students' stress prior to examination. North American Journal of Psychology, 9, 477.

Melco, A. L., Goldman, L., Fine, A., \& Peralta, J. M. (2020). Investigation of physiological and behavioral responses in dogs participating in animal-assisted therapy with children diagnosed with Attention-Deficit Hyperactivity disorder. Journal of Applied Animal Welfare Science, 23(1), 10-28. https://doi.org/10.1080/10888705.2018.1536979

Muckle, J., \& Lasikiewicz, N. (2017). An exploration of the benefits of animal-assisted activities in undergraduate students in Singapore. Asian Journal of Social Psychology, 20(2), 75-84. https://doi.org/10.1111/ajsp.12166

Nimer, J., \& Lundahl, B. (2007). Animal-assisted therapy: A meta-analysis. Anthrozoos: A Multidisciplinary Journal of the Interactions of People \& Animals, 20(3), 225-238. https://doi.org/10.2752/089279307X224773

Nunes, M., Walker, J. R., Syed, T., Jong, M., Stewart, D., Provencher, M. D., ... Furer, P. (2014). A national survey of student extended health insurance programs in postsecondary institutions in Canada: Limited support for students with mental health problems. Canadian Psychology, 55(2), 1-109. Retrieved from https://uwinnipeg.on.worldcat.org/oclc/5585243288

Satici, S. A., Uysal, R., \& Deniz, M. E. (2016). Linking social connectedness to loneliness: the mediating role of subjective happiness. Personality and Individual Differences, 97, 306-310.

Sokal, L. (2020). Balancing benefits and risks of animal-assisted activities (AAA) in childcare centres. Early Childhood Education Journal, 48(3), 273-283. https://doi.org/10.1007/s10643-019-00982-0

Sokal, L., \& Kahl, A. (2019). The effects of animal-assisted activities (AAA) on minority students at a boarding school in Germany. The McGill Journal of Education, 54(3). Retrieved from https://mje.mcgill.ca/article/view/9665/7510

Sokal, L., \& Martin, T. (2021, April). Post-secondary paw patrol: Effects of AAAs on post-secondary students' mental health. Contemporary Journal of Educational Research, 4(1), 24-33. Retrieved from $\mathrm{http}: / /$ redfame.com/journal/index.php/ijce/issue/view/266 
Sokal, L., Woloshyn, D., \& Wilson, A. (in press). Investigating student teaching directors' definitions of "teacher" and paradigms of disability in Canadian teacher education programs. Alberta Journal of Educational Research.

Spruin, E., Dempster, T., Islam, S., \& Raybould, I. (2020). The effects of a therapy dog vs mindfulness vs a student advisor on student anxiety and well-being. Journal of Further and Higher Education. https://doi.org/10.1080/0309877X.2020.1804535

Stern, C., \& Chur-Hansen, A. (2013). Methodological considerations in designing and evaluating animal-assisted interventions. Animals, 3(1), 127-141.

Stewart, L. A., Dispenza, F., Parker, L., Chang, C. Y., \& Cunnien, T. (2014). A pilot study assessing the effectiveness of an animal-assisted outreach program. Journal of Creativity in Mental Health, 9, 332-345.

Sundman, A. E., Van Poucke, A., Holm, S., Faresjö, A., Theodorsson, E., Jensen, P., ... Roth, L. (2019). Long-term stress levels are synchronized in dogs and their owners. Scientific Reports, 9. https://doi.org/7391.10.1038/s41598-019-43851-x

Thelwell, E. (2019). Paws for thought: A controlled study investigating the benefits of interacting with a house-trained $\operatorname{dog}$ on university students' mood and anxiety. Animal (Basel), 9(10). https://doi.org/10.3390/ani9100846

Topp, C., Østergaard, S. D., Søndergaard, S., \& Bech, P. (2015). The WHO-5 Well-Being Index: a systematic review of the literature. Psychotherapy and Psychosomatics, 84(3), 167-76. https://doi.org/10.1159/000376585

Varley, J. (2019). Celebrating the essential. Revista Brasileira De Estudos Da Presença, 9(3). https://doi.org/10.1590/2237-266092877

Walsh, F. (2009). Human-animal bonds 1: The relational significance of companion animals. Family Process, 48(4), 462-480. https://doi.org/10.1111/j.1545-5300.2009.01296.x

Ward-Griffin, E., Klaiber, P., Collins, H., Owens, R., Coren, S., \& Chen, F. (2018). Petting away pre-exam stress: The effect of therapy dog sessions on student well-being. Stress and Health, 34(3), 468-473. https://doi.org/10.1002/smi.2804

Wiens, K., Bhattarai, A., Dores, A., Pedram, P., Williams, J. V. A., Bulloch, A. G. M., ... Patten, S. B. (2020). Mental health among Canadian postsecondary students: A mental health crisis?. The Canadian Journal of Psychiatry, 65(1), 30-35. Retrieved from https://uwinnipeg.on.worldcat.org/oclc/8511191322

World Health Organization [WHO]. (2001). Mental health disorders affect one in four people. Retrieved from https://www.who.int/whr/2001/media_centre/press_release/en/

World Health Organization [WHO]. (2004). Promoting mental health: Concepts, emerging evidence, practice. Geneva: Author.

World Health Organization [WHO]. (2019). Mental health data and statistics. Retrieved from http://www.euro.who.int/en/health-topics/noncommunicable-diseases/mental-health/data-and-resources

Zimmerman, M., Ruggero, C., Chelminski, I., et al.. (2006). Developing brief scales for use in clinical practice: The reliability and validity of single-item measures of depression symptom severity, psychosocial impairment due to depression, and quality of life. Journal of Clinical Psychiatry, 67, 1536-1554.

\section{Copyrights}

Copyright for this article is retained by the author(s), with first publication rights granted to the journal.

This is an open-access article distributed under the terms and conditions of the Creative Commons Attribution license (http://creativecommons.org/licenses/by/4.0/). 